\title{
Draft Genome Sequence of Cumin Blight Pathogen Alternaria burnsii
}

\author{
Zhonghong Feng, ${ }^{1}$ Tom Hsiang, ${ }^{2}$ Xiaofei Liang, ${ }^{1}$ Rong Zhang, ${ }^{1, \dagger}$ and Guangyu Sun ${ }^{1, \dagger}$ \\ ${ }^{1}$ State Key Laboratory of Crop Stress Biology in Arid Areas and College of Plant Protection, Northwest \\ A\&F University, Yangling, Shaanxi Province 712100, China \\ ${ }^{2}$ School of Environmental Sciences, University of Guelph, Guelph, Ontario N1G 2W1, Canada
}

\begin{abstract}
The fungal genus Alternaria consists of highly diverse species. They can be isolated readily from soil, water, and many plants, and even from animals and humans. Alternaria burnsii is a small-spored species of section Alternaria. It has been reported as a pathogen, an endophyte, and a saprophyte, and can also be found in indoor air. It causes cumin blight, a destructive disease on cumin (Cuminum cyminum), and also causes other serious diseases, such as pumpkin seed rot, date palm leaf spot, wheat leaf spot, and gray spot of Notopterygium incisum. In this study, we sequenced and assembled the first genome of $A$. burnsii isolate CBS 107.38. The draft genome can be used as a reference for the further study of related pathogens and comparative genomics of Alternaria species.
\end{abstract}

Alternaria burnsii, Alternaria section Alternaria, is a small-spored species. It is widely distributed in Asia, Europe, America, and Africa, and has been found as a pathogen, a saprophyte, or an endophyte. Cumin blight caused by $A$. burnsii was first reported in India (Uppal et al. 1938). Since then, the disease has been observed in many cumin (Cuminum cyminum L.) growing areas, such as Rajasthan state of India (Mathur 1949), Turkey (Kocaturk 1988; Özer and Bayraktar 2015), Pakistan (Shakir et al. 1995), and Iran (Kamkar et al. 2011). In severe disease years, the yield losses can be up to $70 \%$ (Holliday 1980). In addition, A. burnsii can cause gray leaf spot of the traditional Chinese medicine plant Qianghuo (Notopterygium incisum Ting ex H.T. Chang) (Wang et al. 2009), pumpkin seed rot on Cucurbita maxima Duch. ex Lam. (Paul et al. 2015), leaf spot of date palm (Phoenix dactylifera L.) and wheat (Triticum aestivum L.) (Al-Nadabi et al. 2018), and a leaf disease on common bean (Phaseolus vulgaris L.) (Sendi et al. 2018). A. burnsii was isolated from asymptomatic leaves of Pandanaceae in southern Thailand as an endophyte (Tibpromma et al. 2018). It was also discovered in the indoor air in the United States and considered a saprophyte (Woudenberg et al. 2015a). Genome sequence resources provide fundamental information to explore the molecular mechanisms of species evolution and adaptability. In recent years, genomes of some other Alternaria species have been sequenced (Dang et al. 2015; Hou et al. 2016; Nguyen et al. 2016; Rajarammohan et al. 2019; Wolters et al. 2018; Woudenberg et al. 2015b).

Here, A. burnsii Uppal, Patel \& Kamat CBS 107.38, the type strain isolated from India causing leaf blight on cumin, was selected for whole genome sequencing. The strain was grown on potato dextrose agar (PDA) at $25^{\circ} \mathrm{C}$ in darkness for 7 days, and the colony was used for extraction of total genomic DNA using a modified CTAB procedure (Chen et al. 1993). The genome of $A$. burnsii was sequenced using the Illumina HiSeqX10 platform (Biomarker Technologies, Beijing, China) with paired-end 150 bp reads (insert size of 270 bp and

\footnotetext{
${ }^{\dagger}$ Corresponding authors: G. Y. Sun; sgy@ nwsuaf.edu.cn, R. Zhang; rongzh@nwsuaf.edu.cn
}

The author(s) declare no conflict of interest.

Accepted for publication 24 September 2020

\section{Funding}

This research was supported by the National Natural Science Foundation of China (31972220) and China Agriculture Research System (CARS-27).

\section{Keywords}

genome sequence, cumin blight, Alternaria burnsii, genomics 
Table 1. Genome features of Alternaria burnsii CBS 107.38 and comparisons with two other strains

\begin{tabular}{llll} 
Variables & A. burnsii & $\boldsymbol{A}_{\text {alternata }}$ & ${\text { A. } \text { brassicae }^{\mathbf{b}}}^{\text {a }}$ \\
Sequencing methods & Illumina & Illumina & Nanopore \\
Sequence coverage & $146 \times$ & not available & not available \\
Assembly size (Mb) & 32.97 & 33.12 & 33.77 \\
Number of scaffolds & 72 & 552 & 14 \\
Scaffold N50 (Kbp) & 1,806 & 229 & 3,090 \\
GC content (\%) & 50.90 & 50.90 & 50.98 \\
Number of predicted genes & 11,475 & 11,704 & 11,495 \\
Repeat rate $(\%)$ & 0.91 & not available & 2.43 \\
BUSCO genome completeness $(\%)^{c}$ & 97 & 97 & $96^{d}$ \\
Predicted proteome completeness $(\%)^{\mathrm{c}}$ & 97 & $97^{\text {d }}$ & 98 \\
\hline
\end{tabular}

a Bihon et al. (2016).

b Rajarammohan et al. (2019).

c Completeness $=$ total BUSCOs - fragmented BUSCOs - missing BUSCOs $/$ total BUSCOs $\times 100$

d These results were analyzed in this study.

approximate coverage of 146x). In total, there were 16,519,548 clean reads (around $5 \mathrm{Gbp}$ ), Q30 was up to $94.46 \%$, and GC content was $50.66 \%$. All the clean data was used for de novo assembly using the ABySS assembler v2.0.2 (Simpson et al. 2009). The results showed that the draft genome assembly of $A$. burnsii comprised 72 scaffolds with a total genome size of $32.97 \mathrm{Mbp}$ ( $\mathrm{N} 50=1.81 \mathrm{Mbp}$ ) (Table 1). The number of scaffolds of $A$. burnsii was much lower, and the N50 was higher than those reported for draft genomes generated using second generation sequencing platforms (Dang et al. 2015; Hou et al. 2016) where scaffold numbers ranged from 393 to 31,070 , and N50 length range from 3 to $757 \mathrm{Kbp}$. However, the number of scaffolds was higher than those of assemblies of Alternaria spp. derived from third generation sequencing (Nguyen et al. 2016; Rajarammohan et al. 2019; Wolters et al. 2018). Repetitive sequences across this genome were identified by RepeatMasker v4.0.5 (http://www. repeatmasker.org), with a repeat rate of $0.91 \%$, which was lower than that identified for other Alternaria species, such as Alternaria spp. section Alternaria (1.4-2.7\%), A. solani (1.5\%), A. infectoria (5.3\%), A. brassicicola (7.1\%), A. avenicola (11.9\%), A. papaveraceae $(5.3 \%)$, and $A$. alternantherae (16.5\%) (Woudenberg et al. 2015b). For genome annotation, GeneMark-ES (Ter-Hovhannisyan et al. 2008) was first used for de novo gene structure prediction. The genome assembly and predicted genes of $A$. tagetica was selected as the optimal gene model (according to sensitivity and specificity of gene and exon level) among 24 species of section Alternaria (Dang et al. 2015) trained by Augustus v. 3.1 (Stanke and Morgenstern 2005). Then, MAKER2 v2.31.8 (Holt and Yandell 2011) was used to predict coding genes by integrating gene models predicted from GeneMark-ES and Augustus and protein sequences of the 24 species of section Alternaria (Dang et al. 2015). In total, the A. burnsii genome had 11,907 predicted protein-coding genes.

The software BUSCO v1.2 was used to assess the completeness of the gene predictions with comparison with the universal fungal library fungi_odb9 containing 1,438 single-copy orthologs (Simão et al. 2015) and revealed 97\% completeness with 1,330 single-copy orthologs and 78 duplicated BUSCOs. Only 30 BUSCO orthologs were missing or fragmented. This result was similar to the genomic completeness of $A$. alternata PPRI 21032 (97\%) (Bihon et al. 2016) or A. brassicae J3 (96\%) (Rajarammohan et al. 2019) by BUSCO analysis. This draft genome of $A$. burnsii CBS 107.38 will be useful in the future studies of Alternaria species and is significant for the classification of Alternaria spp. at the whole genomic level.

This draft genome assembly, version 1, has been deposited at GenBank under the accession number JAAABM000000000 (BioProject: PRJNA600135; BioSample: SAMN13783390).

\section{Literature Cited}

Al-Nadabi, H. H., Maharachchikumbura, S. S. N., Agrama, H., Al-Azri, M., Nasehi, A., and Al-Sadi, A. M. 2018. Molecular characterization and pathogenicity of Alternaria species on wheat and date palms in Oman. Eur. J. Plant Pathol. 152: 577-588.
Bihon, W., Cloete, M., Gerrano, A. S., Oelofse, D., and Adebola, P. 2016. Draft genome sequence of Alternaria alternata isolated from onion leaves in South Africa. Genome Announc. 4:e01022-16.

Chen, X. M., Line, R. F., and Leung, H. 1993. Relationship between virulence variation and DNA polymorphism in Puccinia strifformis. Phytopathology 83:1489-1497. 
Dang, H. X., Pryor, B., Peever, T., and Lawrence, C. B. 2015. The Alternaria genomes database: a comprehensive resource for a fungal genus comprised of saprophytes, plant pathogens, and allergenic species. BMC Genomics 16:239.

Holliday, P. 1980. Pages 289-295 in: Fungus Diseases of Tropical Crops. Cambridge University Press, Cambridge, U. K.

Holt, C., and Yandell, M. 2011. MAKER2: an annotation pipeline and genomedatabase management tool for second-generation genome projects. BMC Bioinformatics 12:491.

Hou, Y. J., Ma, X., Wan, W. T., Long, N., Zhang, J., Tan, Y. T., Duan, S. C., Zeng, Y., and Dong, Y. 2016. Comparative genomics of pathogens causing brown spot disease of tobacco: Alternaria longipes and Alternaria alternata. PLoS One 11: e0155258.

Kamkar, B., Koocheki, A., Mahallati, M. N., da Silva, J. A. T., Moghaddam, P. R., and Kafi, M. 2011. Fungal diseases and inappropriate sowing dates, the most important reducing factors in cumin fields of Iran, a case study in Khorasan provinces. Crop Prot. 30:208-215.

Kocaturk, S. 1988. The important cumin diseases in Central Anatolia. J. Turk. Phytopathol. 17:121.

Mathur, R. L. 1949. Plant protection notes and newsclaipur. PI. Prot. Bull. Govt. India. $1: 30$.

Nguyen, H. D. T., Lewis, C. T., Lévesque, C. A., and Grfenhan, T. 2016. Draft genome sequence of Alternaria alternata ATCC 34957. Genome Announc. 4:e01554-15.

Özer, G., and Bayraktar, H. 2015. Determination of fungal pathogens associated with Cuminum cyminum in Turkey.Plant Protec. Sci. 51:74-79.

Paul, N. C., Deng, J. X., Lee, H. B., and Yu, S. H. 2015. Characterization and pathogenicity of Alternaria burnsii from seeds of Cucurbita maxima (Cucurbitaceae) in Bangladesh. Mycobiology 43:384-391.

Rajarammohan, S., Paritosh, K., Pental, D., and Kaur, J. 2019. Comparative genomics of Alternaria species provides insights into the pathogenic lifestyle of Alternaria brassicae - a pathogen of the Brassicaceae family. BMC Genomics 20: 1036.

Sendi, Y., Ben-Romdhane, S., Mhamdi, R., and Mrabet, M. 2018. Diversity and geographic distribution of fungal strains infecting field-grown common bean (Phaseolus vulgaris L.) in Tunisia. Eur. J. Plant Pathol. 153:947-955.
Shakir, A. S., Mirza, J. H., Sahi, S. T., and Ansar, M. 1995. First report of Alternaria burnsii, the causal organism of cumin blight in Pakistan. Pak. J. Phytopathol. 7: 219-223.

Simão, F. A., Waterhouse, R. M., loannidis, P., Kriventseva, E. V., and Zdobnov, E. M. 2015. BUSCO: assessing genome assembly and annotation completeness with single-copy orthologs. Bioinformatics 31:3210-3212.

Simpson, J. T., Wong, K., Jackman, S. D., Schein, J. E., Jones, S. J., and Birol, I. 2009. ABySS: A parallel assembler for short read sequence data. Genome Res. 19:1117-1123.

Stanke, M., and Morgenstern, B. 2005. AUGUSTUS: a web server for gene prediction in eukaryotes that allows user-defined constraints. Nucleic Acids Res. 33: W465-W467.

Ter-Hovhannisyan, V., Lomsadze, A., Chernoff, Y. O., and Borodovsky, M. 2008. Gene prediction in novel fungal genomes using an ab initio algorithm with unsupervised training. Genome Res. 18:1979-1990.

Tibpromma, S., Hyde, K. D., Bhat, J. D., Mortimer, P. E., Xu, J., Promputtha, I., Doilom, M., Yang, J., Tang, A. M. C., and Karunarathna, S. C. 2018. Identification of endophytic fungi from leaves of Pandanaceae based on their morphotypes and DNA sequence data from southern Thailand. MycoKeys 33:25-67.

Uppal, B. N., Patel, M. K., and Kamal, M. N. 1938. Alternaria blight of cumin. Indian J. Agric. Sci. 8:9-62.

Wang, Y., Chen, X., Du, T., Xue, L., and Jin, L. 2009. Disease survey and pathogen identification on Notopterygium incisum in Gansu Province. China J. Chin. Mater. Med. 34:1898-1901.

Wolters, P. J., Faino, L., Trudy, V. D. B., Evenhuis, B., Visser, R., Seidl, M. F., and Vleeshouwers, V. G. A. A. 2018. Gapless genome assembly of the potato and tomato early blight pathogen Alternaria solani. Mol. Plant-Microbe Interact. 31: 692-694.

Woudenberg, J. H. C., Seidl, M. F., Groenewald, J. Z., de Vries, M., Stielow, J. B., Thomma, B. P. H. J., and Crous, P. W. 2015b. Alternaria section Alternaria: Species, formae speciales or pathotypes? Stud. Mycol. 82:1-21.

Woudenberg, J. H. C., Van, M. N. A., Jurjević, Ž., Groenewald, J. Z., and Crous, P. W. 2015a. Diversity and movement of indoor Alternaria alternata across the mainland USA. Fungal Genet. Biol. 81:62-72. 